\title{
Relationship between optical extinction and liquid water content in fogs
}

\author{
C. Klein and A. Dabas \\ du CNRS, Toulouse, France \\ Correspondence to: A. Dabas (alain.dabas@meteo.fr) \\ Received: 27 August 2013 - Published in Atmos. Meas. Tech. Discuss.: 8 November 2013 \\ Revised: 28 February 2014 - Accepted: 2 April 2014 - Published: 16 May 2014
}

Groupe d'Étude de l'Atmosphère Météorologique (GAME), Unité Mixte de Recherche 3985 (UMR3589) de Météo-France et

\begin{abstract}
Studies carried out in the late 1970s suggest that a simple linear relationship exists in practice between the optical extinction in the thermal IR and the liquid water content (LWC) in fogs. Such a relationship opens the possibility to monitor the vertical profile of the LWC in fogs with a rather simple backscatter lidar. Little is known on how the LWC varies as a function of height and during the fog life cycle, so the new measurement technique would help understand fog physics and provide valuable data for improving the quality of fog forecasts. In this paper, the validity of the linear relationship is revisited in the light of recent observations of fog droplet size distributions measured with a combination of sensors covering a large range of droplet radii. In particular, large droplets (radius above $15 \mu \mathrm{m}$ ) are now detected, which was not the case in the late 1970 s. The results confirm that the linear relationship still holds, at least for the mostly radiative fogs observed during the campaign. The impact of the precise value of the real and imaginary parts of the refractive index on the coefficient of the linear relationship is also studied. The usual practice considers that droplets are made of pure water. This assumption is probably valid for big drops, but it may be questioned for small ones since droplets are formed from condensation nuclei of highly variable chemical composition. The study suggests that the precise nature of condensation nuclei will primarily affect rather light fogs with small droplets and light liquid water contents.
\end{abstract}

\section{Introduction}

Improving the quality of fog forecasts is a challenge for weather prediction centres. Fog is indeed a common weather phenomenon with a strong, adverse impact on many human activities. This is particularly true for road traffic and aviation. Road accidents caused by fog are regularly reported in the media. In aviation, the worst crash happened in 1977 in Tenerife when two Boing 747 jumbo jets collided on the runway causing the death of more than 500 persons. The investigation (see ICAO Circular 135/AN156) concluded that the dense fog at the airport was a key factor. Hopefully, such severe events are rare, but the aviation industry is particularly vulnerable to fog as safety regulations at airports limit the capacity of runways when the visibility is poor (e.g. runway visual range below $600 \mathrm{~m}$ at Paris Roissy Charles-de-Gaulle Airport). This leads to costly delays, missed connections and cancellations (see Sullivan and Jordan, 2006, for a description of possible disruptions to a major airport like London Heathrow).

Many research centres around the world work on fog physics and fog numerical simulation. The final objective is to develop operational tools for accurate prediction of the formation and dissipation of fog several hours in advance. If such tools were existing, airports and aviation companies could warn the passengers, encourage them to cancel their flight, and mitigate the impact by an adequate organization of the time slots still available. Ships would know when their arrival at the destination harbour would be delayed. Drivers could be encouraged to postpone their trips and thus avoid dangerous traffic conditions. Roads could even be closed, as is the case when icy conditions are predicted. 
Weather conditions favourable to fog formation are well known and predictable, but accurate predictions of the time of formation and dissipation is presently an unmet challenge. The reason is that fog is a local phenomenon with a small vertical extension (several hundreds of metres at most) and it involves several small-scale, highly nonlinear processes. These processes are not always fully understood and they are anyway all difficult to represent in numerical models (a complete review of the state of the art in fog physics can be found in Gultepe, 2007). Such processes include e.g. radiative transfer, turbulence and activation of aerosols into water drops.

Several directions are currently pursued for improving our understanding of fog and ultimately its forecast. One of them deals with the observation. Current observation systems provide useful information but are operated at the ground and characterize the state of the atmosphere in the lowest metres and not above. Observation systems for altitude measurements used operationally or for research are ill adapted. Research aircraft for instance cannot fly in fog - fogs are thin, so they would have to fly close to the ground in poor visibility. Instrumented masts are possible, but are expensive and are deployed with difficulty close to airfields. Free or tethered balloons are another possibility, but they are "single shot" (free balloons) or imply complex operations that limit their practical usefulness (Dabas et al., 2012). Remote sensors would offer many advantages. Deployed on the ground, they can be operated unattended for long periods of time. As an instance, Paris Charles-de-Gaulle Airport has been equipped with a sodar since 2008. It detects the top height of fog layers and provides this information to the operational fog prediction system COBEL (Dabas et al., 2012; Bergot and Guédalia, 1994).

The work reported in this paper is part of an effort aimed at developing a lidar able to measure vertical profiles of the liquid water content (LWC). The LWC can be measured at ground (Gerber, 1991), but altitude measurements are scarce because they are difficult to achieve with current sensors. Observations are thus lacking for validating model simulations (Bergot, 2013). Real-time LWC observation could have a significant impact on fog predictions (Rémy and Bergot, 2009). In this work, the possibility of measuring the LWC with a lidar is based on the existence of a relationship between the LWC and the optical extinction in fogs. Such a relationship was postulated by Chylek (1978) in the late 1970s and tested experimentally by Pinnick et al. (1979) in the same period. In principle, lidars can measure extinction coefficients. Due to the strong optical extinction in fogs their range is limited but fogs are thin (a few tens to a few hundreds of metres) so it should be possible to obtain useful measurements.

The experimental validation of Pinnick et al. (1979) was based on a particle counter and sizer developed by Particle Measurement Systems Inc. in the 1970s. The sensor is described by Pinnick et al. (1978). According to that paper, a major limitation was that particles with radii $>15 \mu \mathrm{m}$ were only partially detected due to losses in the ventilated collection tube. Thus the impact of larger droplets in fogs, if any, could not be evaluated. A second limitation was that extinction coefficients were computed using Mie theory with refraction indices of pure water. The refraction index of large droplets is probably close to pure water because they mostly contain water. However, drops are formed from condensation nuclei - that is, aerosols (Pruppacher and Klett, 2010). Their refraction index depends on their chemical composition (Fenn et al., 1985; Guyon et al., 2003). In fogs, many droplets are small with diameters of the order of a micron or less. They contribute significantly to the extinction through scattering. The relative contribution of their condensation nucleus to their chemical composition might not be negligible and impacts their refraction index.

The purpose of this paper is twofold. First, the Pinnick et al. (1979) results are revisited on the basis of observations carried out recently with a state-of-the art instrumental setup. Described in Sect. 2, the setup can in principle detect and size fog droplets up to a diameter of $50 \mu \mathrm{m}$. In Sect. 3, the linear relationship between optical extinction and LWC in fogs is checked. Then the potential impact of the refractive index is studied (Sect. 4). As there are very few measurements of the refractive index of fog droplets, the study determines how far indices can deviate from pure water before the extinction to LWC relationship is significantly impacted. Conclusions are drawn in Sect. 5.

\section{Experimental setup and data}

The size distributions used in this paper were measured during a field experiment called PARISFOG (Haeffelin et al., 2010) in the frame of the research study PREVIBOSS (Elias et al., 2012). This study was designed to improve the understanding of processes involved in the life cycle of fog. It was held at Site Instrumental de Recherche en Télédétection Atmosphérique (SIRTA) located $25 \mathrm{~km}$ south of Paris (Heaffelin et al., 2005). Data were monitored during the winters 2010/2011 and 2011/2012. Aerosol and fog particle size distributions were measured with two instruments: a Welas 2000, and a Fog Monitor FM 100 (Burnet et al., 2012).

Manufactured by PALAS, the Welas 2000 measures the concentration and size of particles by looking at the $90^{\circ}$ scattering of a white light source. The size range depends on instrumental settings and type of particles. During PARISFOG, the system was expected to measure water particles from diameters of $0.4 \mu \mathrm{m}$ to about $20 \mu \mathrm{m}$. The instrument was $3 \mathrm{~m}$ above the ground.

The FM 100 is manufactured by Droplet Measurement Technologies (DMT). It is a forward scattering spectrometer probe placed in a wind tunnel with active ventilation. The FM 100 detects particles in the diameter range 2-50 $\mu \mathrm{m}$. The size distributions used in this paper are retrieved with the manufacturer's software delivered with the FM 100. The 
actual performance of the FM 100 is discussed in Spiegel et al. (2012).

The Welas 2000 and the FM 100 are complementary sensors. The Welas 2000 measures small particles (up to a few microns), and the FM 100 the large ones (up to several tens of microns). Intermediate sizes are detected by both, so the consistency of their size distributions can be checked. Both instruments were calibrated before the campaigns with glass or latex beads, but the estimation of detected droplets is done with a calibration curve that assumes the droplets are made of water. The Welas 2000 and FM 100 were time synchronized.

Composite size distributions from both instruments were built and fitted with the sum of $M$ log-normal modes:

$n(r)=\frac{1}{\sqrt{2 \pi} r} \sum_{k=1}^{M} \frac{N_{k}}{\ln \left(\sigma_{k}\right)} \exp \left[-\frac{1}{2 \ln ^{2}\left(\sigma_{k}\right)} \ln \left(\frac{r}{r_{k}}\right)^{2}\right]$.

Here, $n(r)$ is in part. $\mu \mathrm{m}^{-1} \mathrm{~m}^{-3}, r$ is the particle radius (in $\mu \mathrm{m}$ ), $r_{k}$ is the modal radius (in $\mu \mathrm{m}$ ), $\sigma_{k}$ sets the width of the mode, and $N_{k}$ in part. $\mathrm{m}^{-3}$ is the concentration of the mode. In practice, we used a maximum of $M=4$ modes.

The composite distributions were made in the following way. Three size classes of the FM 100 overlap the size sensitivity range of the Welas 2000. Below these classes, the composite distribution is derived from the Welas 2000. Above, FM 100 measurements are considered. In the overlapping region, an average of both is taken.

The following sections are based on 20 different size distributions selected among several hundreds of size distributions observed during PARISFOG. The selection was done so as to cover a wide range of liquid water contents while keeping the number of cases to a reasonable value. In practice, the 20 cases were observed during three fog episodes. The lognormal mode characteristics as well as the total liquid water contents are given in Table 1. The log-normal modes were fitted to the measured size distributions. The fitting procedure is based on an Excel code. The parameters of up to four modes are entered manually. The synthetic size distribution given by Eq. (1) is then automatically drawn on a log-log plot and compared to the observed size distribution. The parameters are manually tuned until a good fit is achieved. A fit example is shown in Fig. 1. There the number of particles counted in the various classes of the FM 100 and Welas 2000 are displayed with dots. The fit is represented with the solid line. The individual modes are indicated with dashes. The size distribution was observed on 19 November 2010, at 05:40 UTC (06:40 LST). A mode of large particles is detected. Its modal radius is $7.5 \mu \mathrm{m}$ (diameter $15 \mu \mathrm{m}$ ). The figure confirms the ability of the FM100 to detect and count large particles. In the present example, droplets with diameters $>15 \mu \mathrm{m}$ are indeed detected. Although their number is small, their contribution to the overall LWC is large (more than $70 \%$ in the present case).

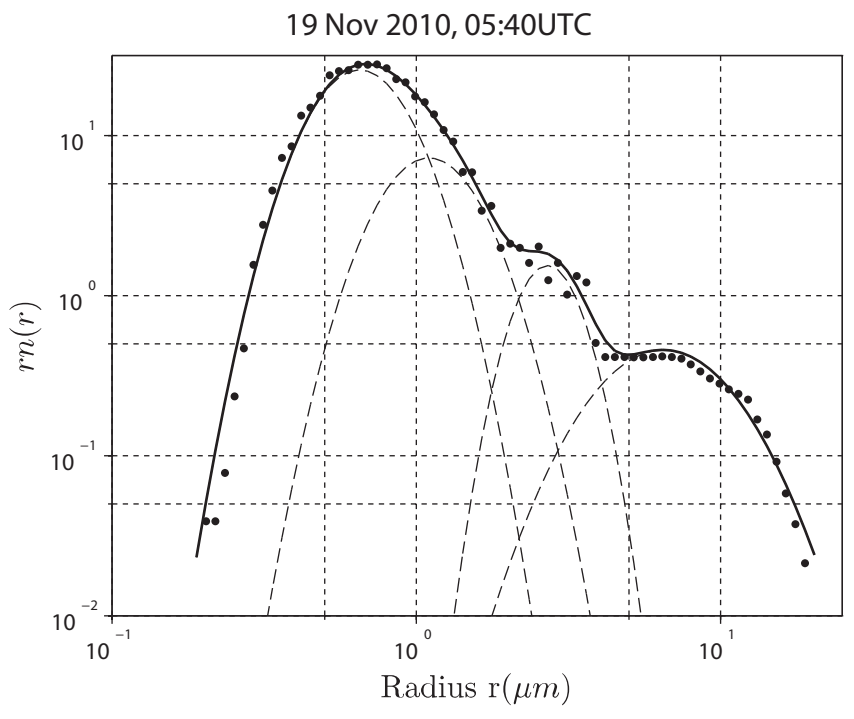

Fig. 1. Composite size distribution measured by Welas 2000 and FM100 on 19 November 2010, at 05:40 UTC. The measurements are the dots. A sum of $M=4 \log$-normal modes are fitted. Each mode is represented by dashes. The sum fitted to the measurements is the thick, solid line. The parameters of the modes are given in Table 1 (fog case 10).

\section{LWC versus extinction}

The liquid water content $W$ in $\mathrm{g} \mathrm{m}^{-3}$ is given by the thirdorder moment of the size distribution

$W=\frac{4 \pi \rho_{\mathrm{H}_{2} \mathrm{O}}}{3} \int_{0}^{+\infty} r^{3} n(r) \mathrm{d} r$,

where $\rho_{\mathrm{H}_{2} \mathrm{O}}=10^{-12} \mathrm{~g} \mathrm{\mu m}^{-3}$ is the density of water. As for the extinction coefficients $\alpha(\lambda)$ (in $\mathrm{m}^{-1}$ ), we have

$\alpha(\lambda)=10^{-12} \pi \int_{0}^{+\infty} r^{2} Q_{\text {ext }}(r, \lambda, m) n(r) \mathrm{d} r$

with $Q_{\text {ext }}(r, \lambda, m)$ the extinction efficiency (Bohren and Huffman, 1983) for the particles of radius $r$ (in $\mu \mathrm{m}$ ), the refraction index $m$, at the wavelength $\lambda$ (in $\mu \mathrm{m}$ ).

For spherical, homogeneous particles, $Q_{\text {ext }}(r, \lambda, m)$ is given by Mie theory (Mie, 1908). A Fortran code can be found for its computation in Bohren and Huffman (1983). For this work we used a Matlab adaption from Mätzler (2002). The typical behaviour of $Q_{\text {ext }}(r, \lambda, m)$ is shown in Fig. 2. There $Q_{\text {ext }}(r, \lambda, m)$ is drawn as a function of the size parameter $2 \pi r / \lambda$ for $\lambda=4 \mu \mathrm{m}$ and $\lambda=11 \mu \mathrm{m}$. For the refractive index of the particle, we considered pure water with values taken from Hale and Querry (1973) $(1.351+$ $i 0.00460 @ \lambda=4 \mu \mathrm{m}$ and $1.153+i 0.0968 @ \lambda=11 \mu \mathrm{m})$. 
Table 1. Log-normal mode characteristics of the $20 \mathrm{fog}$ size distributions used in this paper. $D_{k}$ is the modal diameter (equal to $2 r_{k}$ ).

\begin{tabular}{|c|c|c|c|c|c|c|c|c|c|c|c|}
\hline \multirow{2}{*}{ \# } & \multirow{2}{*}{ Date } & \multirow{2}{*}{ Time (UTC) } & \multirow{2}{*}{ Mode } & \multirow{2}{*}{$N_{k}($ part/cc $)$} & \multirow{2}{*}{$k$} & \multirow{2}{*}{$D_{k}(\mu \mathrm{m})$} & \multirow{2}{*}{$\operatorname{LWC}\left(\mathrm{g} \mathrm{m}^{-3}\right)$} & \multicolumn{2}{|c|}{$=11 \mu \mathrm{m}$} & \multicolumn{2}{|c|}{$=4 \mu \mathrm{m}$} \\
\hline & & & & & & & & $\begin{array}{l}\text { ext } \\
\left(\mathrm{m}^{-1}\right)\end{array}$ & $\begin{array}{l}\mathrm{abs} \\
\left(\mathrm{m}^{-1}\right)\end{array}$ & $\begin{array}{l}\text { ext } \\
\left(\mathrm{m}^{-1}\right)\end{array}$ & $\begin{array}{l}\mathrm{abs} \\
\left(\mathrm{m}^{-1}\right)\end{array}$ \\
\hline \multirow[b]{2}{*}{1} & \multirow[b]{2}{*}{$19 / 11 / 2010$} & \multirow[b]{2}{*}{ 03:00 } & 1 & 44 & 1.3 & 0.92 & \multirow[b]{2}{*}{$6.89 \mathrm{E}-05$} & \multirow[b]{2}{*}{$7.80 \mathrm{E}-06$} & & & \\
\hline & & & 2 & 7 & 1.5 & 1.8 & & & 7.40E-06 & $2.70 \mathrm{E}-05$ & $1.30 \mathrm{E}-06$ \\
\hline 2 & $16 / 11 / 2010$ & $21 \cdot 00$ & 1 & 200 & 1.3 & 0.95 & $176 \mathrm{~F}_{-}-04$ & $189 E_{-} 05$ & $186 E_{-} 05$ & $341 \mathrm{~F}_{-} 05$ & $280 \mathrm{~F}_{-}-06$ \\
\hline 2 & $16 / 11 / 2010$ & 21:00 & 2 & 15 & 1.2 & 1.8 & $1.76 \mathrm{E}-04$ & $1.89 \mathrm{E}-05$ & $1.86 \mathrm{E}-05$ & $3.41 \mathrm{E}-05$ & $2.80 \mathrm{E}-06$ \\
\hline 3 & 1611/1001 & 00.52 & 1 & 225 & 1.3 & 0.88 & 188504 & $201 \mathrm{~F} 05$ & 100505 & 312505 & 300506 \\
\hline 3 & $16 / 11 / 2011$ & $00: 52$ & 2 & 50 & 1.3 & 1.3 & $1.88 \mathrm{E}-04$ & $2.01 \mathrm{E}-05$ & $1.99 \mathrm{E}-05$ & $3.12 \mathrm{E}-05$ & $3.00 \mathrm{E}-06$ \\
\hline & & & 1 & 275 & 1.28 & 0.85 & & & & & \\
\hline 4 & $16 / 11 / 2011$ & $00: 57$ & 2 & 95 & 1.25 & 1.35 & $3.15 \mathrm{E}-04$ & $3.40 \mathrm{E}-05$ & $3.34 \mathrm{E}-05$ & $6.72 \mathrm{E}-05$ & $5.20 \mathrm{E}-06$ \\
\hline & & & 3 & 7 & 1.2 & 2.2 & & & & & \\
\hline 5 & $19 / 11 / 2010$ & 05.00 & 1 & 250 & 1.33 & 1.08 & $366 \mathrm{E}-04$ & $406 \mathrm{E}-05$ & $3.90 \mathrm{E}-05$ & $1.18 \mathrm{E}-04$ & $6.40 \mathrm{E}-06$ \\
\hline & & 05.00 & 2 & 20 & 1.5 & 1.8 & $3.00 \mathrm{E}-\mathrm{U} 4$ & $4.00 \mathrm{E}-\mathrm{UD}$ & $3.90 \mathrm{E}-05$ & & \\
\hline & & & 1 & 320 & 1.28 & 0.88 & & & & & \\
\hline & & & 2 & 95 & 1.25 & 1.3 & & & & & \\
\hline 6 & $16 / 11 / 2011$ & 01:02 & 3 & 5 & 1.2 & 2.2 & 1.17E-03 & $1.50 \mathrm{E}-04$ & $1.18 \mathrm{E}-04$ & $6.26 \mathrm{E}-04$ & 2.47E-05 \\
\hline & & & 4 & 5 & 1.35 & 6 & & & & & \\
\hline & & & 1 & 830 & 1.34 & 1.1 & & & & & \\
\hline 7 & $16 / 11 / 2010$ & $22: 00$ & 2 & 160 & 1.23 & 1.9 & $2.62 \mathrm{E}-03$ & $2.92 \mathrm{E}-04$ & $2.81 \mathrm{E}-04$ & $1.13 \mathrm{E}-03$ & $4.95 \mathrm{E}-05$ \\
\hline & & & 3 & 70 & 1.4 & 2.5 & & & & & \\
\hline & & & 1 & 280 & 1.28 & 0.85 & & & & & \\
\hline & & & 2 & 250 & 1.3 & 1.28 & & & & & \\
\hline 8 & $16 / 11 / 2011$ & 01:07 & 3 & 20 & 1.2 & 2.3 & 7.63E-03 & $1.02 \mathrm{E}-03$ & 6.64E-04 & $2.83 \mathrm{E}-03$ & $1.68 \mathrm{E}-04$ \\
\hline & & & 4 & 18 & 1.6 & 6.5 & & & & & \\
\hline & & & 1 & 875 & 1.35 & 1.1 & & & & & \\
\hline & & & 2 & 200 & 1.3 & 2 & & & & & \\
\hline 9 & $16 / 11 / 2010$ & $22: 15$ & 3 & 100 & 1.55 & 2.4 & $9.72 \mathrm{E}-03$ & $1.25 \mathrm{E}-03$ & $9.58 \mathrm{E}-04$ & $5.09 \mathrm{E}-03$ & $2.09 \mathrm{E}-04$ \\
\hline & & & 4 & 50 & 1.7 & 4 & & & & & \\
\hline & & & 1 & 295 & 1.39 & 1.3 & & & & & \\
\hline & & & 2 & 85 & 1.4 & 2.2 & & & & & \\
\hline 10 & $19 / 11 / 2010$ & $05: 40$ & 3 & 12 & 1.25 & 5.4 & 2.64E-02 & $2.87 \mathrm{E}-03$ & $1.57 \mathrm{E}-03$ & $4.86 \mathrm{E}-03$ & $5.01 \mathrm{E}-04$ \\
\hline & & & 4 & 5 & 1.6 & 15 & & & & & \\
\hline & & & 1 & 500 & 1.28 & 0.89 & & & & & \\
\hline & & & 2 & 350 & 1.3 & 1.5 & & & & & \\
\hline 11 & $16 / 11 / 2011$ & $01: 12$ & 3 & 20 & 1.18 & 2.8 & $5.57 \mathrm{E}-02$ & 5.57E-03 & $3.07 \mathrm{E}-03$ & 9.37E-03 & $1.01 \mathrm{E}-03$ \\
\hline & & & 4 & 60 & 2.3 & 4.4 & & & & & \\
\hline & & & 1 & 170 & 1.39 & 1.3 & & & & & \\
\hline 12 & & & 2 & 85 & 1.45 & 2.18 & & & & & \\
\hline 12 & 19/11/2010 & 06:50 & 3 & 42 & 1.39 & 4.88 & $4.72 \mathrm{E}-02$ & $6.14 \mathrm{E}-03$ & $3.53 \mathrm{E}-03$ & $1.23 \mathrm{E}-02$ & $1.01 \mathrm{E}-03$ \\
\hline & & & 4 & 22 & 1.45 & 12.5 & & & & & \\
\hline & & & 1 & 490 & 1.3 & 0.9 & & & & & \\
\hline & & & 2 & 475 & 1.4 & 1.55 & & & & & \\
\hline 13 & $16 / 11 / 2011$ & 01:17 & 3 & 45 & 1.5 & 3.1 & $5.44 \mathrm{E}-02$ & 7.06E-03 & $4.08 \mathrm{E}-03$ & 1.32E-02 & $1.16 \mathrm{E}-03$ \\
\hline & & & 4 & 35 & 1.5 & 11 & & & & & \\
\hline & & & 1 & 865 & 1.33 & 1 & & & & & \\
\hline & & & 2 & 700 & 1.38 & 1.6 & & & & & \\
\hline 14 & $16 / 11 / 2011$ & 09:22 & 3 & 195 & 1.55 & 4.5 & $5.77 \mathrm{E}-02$ & 7.87E-03 & $5.18 \mathrm{E}-03$ & $2.34 \mathrm{E}-02$ & $1.30 \mathrm{E}-03$ \\
\hline & & & 4 & 30 & 1.3 & 11.5 & & & & & \\
\hline & & & 1 & 535 & 1.31 & 0.9 & & & & & \\
\hline & & & 2 & 510 & 1.4 & 1.56 & & & & & \\
\hline 15 & $16 / 11 / 2011$ & 01:27 & 3 & 95 & 1.6 & 3 & $6.59 \mathrm{E}-02$ & 8.73E-03 & $5.21 \mathrm{E}-03$ & $1.86 \mathrm{E}-02$ & $1.44 \mathrm{E}-03$ \\
\hline & & & 4 & 55 & 1.5 & 10 & & & & & \\
\hline & & & 1 & 315 & 1.35 & 1 & & & & & \\
\hline & & & 2 & 300 & 1.38 & 1.62 & & & & & \\
\hline 16 & $16 / 11 / 2011$ & $08: 15$ & 3 & 145 & 1.6 & 5 & $6.71 \mathrm{E}-02$ & $9.25 \mathrm{E}-03$ & $5.87 \mathrm{E}-03$ & $2.48 \mathrm{E}-02$ & $1.52 \mathrm{E}-03$ \\
\hline & & & 4 & 40 & 1.3 & 11.2 & & & & & \\
\hline
\end{tabular}


Table 1. Continued.

\begin{tabular}{|c|c|c|c|c|c|c|c|c|c|c|c|}
\hline \multirow[t]{2}{*}{ \# } & \multirow{2}{*}{ Date } & \multirow{2}{*}{\multicolumn{2}{|c|}{ Time (UTC) Mode }} & \multirow{2}{*}{$N_{k}($ part/cc $)$} & \multirow{2}{*}{$k$} & \multirow{2}{*}{$D_{k}(\mu \mathrm{m})$} & \multirow{2}{*}{$\operatorname{LWC}\left(\mathrm{g} \mathrm{m}^{-3}\right)$} & \multicolumn{2}{|c|}{$=11 \mu \mathrm{m}$} & \multicolumn{2}{|c|}{$=4 \mu \mathrm{m}$} \\
\hline & & & & & & & & $\begin{array}{l}\mathrm{ext} \\
\left(\mathrm{m}^{-1}\right)\end{array}$ & $\begin{array}{l}\mathrm{abs} \\
\left(\mathrm{m}^{-1}\right)\end{array}$ & $\begin{array}{l}\text { ext } \\
\left(\mathrm{m}^{-1}\right)\end{array}$ & $\begin{array}{l}\mathrm{abs} \\
\left(\mathrm{m}^{-1}\right)\end{array}$ \\
\hline \multirow{4}{*}{17} & \multirow{4}{*}{$16 / 11 / 2011$} & \multirow{4}{*}{ 05:47 } & 1 & 210 & 1.35 & 1.03 & \multirow{4}{*}{ 9.04E-02 } & \multirow{4}{*}{$1.24 \mathrm{E}-02$} & \multirow{4}{*}{$7.56 \mathrm{E}-03$} & \multirow{4}{*}{$2.90 \mathrm{E}-02$} & \multirow{4}{*}{$2.03 \mathrm{E}-03$} \\
\hline & & & 2 & 290 & 1.55 & 1.9 & & & & & \\
\hline & & & 3 & 70 & 1.28 & 5.6 & & & & & \\
\hline & & & 4 & 70 & 1.35 & 11.3 & & & & & \\
\hline \multirow{4}{*}{18} & \multirow{4}{*}{$16 / 11 / 2011$} & \multirow{4}{*}{ 04:42 } & 1 & 235 & 1.4 & 1.06 & \multirow{4}{*}{$9.22 \mathrm{E}-02$} & \multirow{4}{*}{$1.26 \mathrm{E}-02$} & \multirow{4}{*}{ 7.65E-03 } & \multirow{4}{*}{$2.81 \mathrm{E}-02$} & \multirow{4}{*}{$2.07 \mathrm{E}-03$} \\
\hline & & & 2 & 245 & 1.45 & 1.75 & & & & & \\
\hline & & & 3 & 80 & 1.6 & 5 & & & & & \\
\hline & & & 4 & 68 & 1.36 & 11.2 & & & & & \\
\hline \multirow{4}{*}{19} & \multirow{4}{*}{$16 / 11 / 2010$} & \multirow{4}{*}{ 23:00 } & 1 & 1150 & 1.34 & 1.07 & \multirow{4}{*}{$1.29 \mathrm{E}-01$} & \multirow{4}{*}{$1.31 \mathrm{E}-02$} & \multirow{4}{*}{$7.28 \mathrm{E}-03$} & \multirow{4}{*}{$2.28 \mathrm{E}-02$} & \multirow{4}{*}{$2.37 \mathrm{E}-03$} \\
\hline & & & 2 & 350 & 1.32 & 2 & & & & & \\
\hline & & & 3 & 80 & 2 & 3 & & & & & \\
\hline & & & 4 & 80 & 2.15 & 6 & & & & & \\
\hline \multirow{4}{*}{20} & & & 1 & 330 & 1.34 & 1.07 & & & & & \\
\hline & & & 2 & 230 & 1.44 & 2 & & & & & \\
\hline & $17 / 11 / 2010$ & $00: 10$ & 3 & 25 & 1.3 & 6.3 & $1.25 \mathrm{E}-01$ & $1.36 \mathrm{E}-02$ & $7.18 \mathrm{E}-03$ & $2.05 \mathrm{E}-02$ & $2.39 \mathrm{E}-03$ \\
\hline & & & 4 & 25 & 1.6 & 15 & & & & & \\
\hline
\end{tabular}

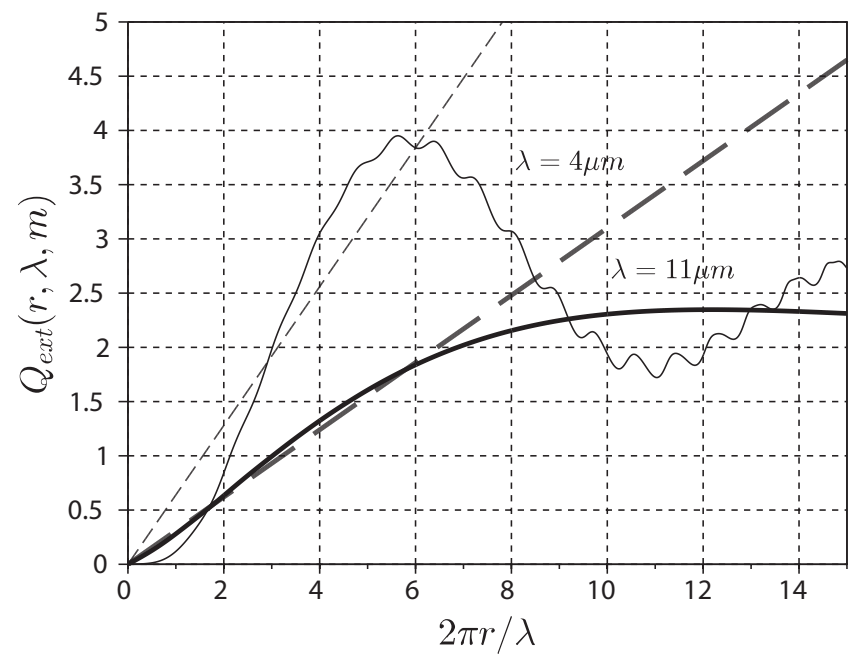

Fig. 2. Extinction efficiency $Q_{\text {ext }}(r, \lambda, m)$ as a function of the size parameter $2 \pi r / \lambda$ for $\lambda=4 \mu \mathrm{m}$ (thin line) and $\lambda=11 \mu \mathrm{m}$ (thick line). $Q_{\text {ext }}(r, \lambda, m)$ was computed with the Matlab implementation of Mie theory by Mätzler (2002). The dashes show the linear approximations (thin $=4 \mu \mathrm{m}$; thick $=11 \mu \mathrm{m}$ ) suggested by Chylek (1978).

Considering the typical behaviour of $Q_{\text {ext }}(r, \lambda, m)$, Chylek (1978) suggested that the extinction efficiency could be reasonably well approximated by a linear relationship

$Q_{\mathrm{ext}}(r, \lambda, m) \approx c_{\mathrm{e}}(\lambda) \frac{2 \pi r}{\lambda}$

for radii $r$ smaller than a maximum radius $r_{\mathrm{m}}$. Pinnick et al. (1979) proposed values for $c_{\mathrm{e}}(\lambda)$. The linear approximations for $\lambda=4 \mu \mathrm{m}$ and $\lambda=11 \mu \mathrm{m}$ are drawn with dashes on Fig. 2. The maximum radius $r_{\mathrm{m}}$ is of the order of the wavelength $\lambda$.
Combining Eqs. (3) and (4), it appears that the liquid water content $W$ can be related to the extinction coefficient $\alpha(\lambda)$ through a simple, linear equation independent of the actual size distribution $n(r)$ :

$\hat{W} \approx \frac{210^{12} \lambda \rho_{\mathrm{H}_{2} \mathrm{O}}}{3 \pi c_{\mathrm{e}}(\lambda)} \alpha(\lambda)$

Using Eqs. (2) and (3), the liquid water contents and extinction coefficients of the 20 selected size distributions were derived for the wavelengths $\lambda$ studied in Pinnick et al. (1979).

The 20 PARISFOG size distributions vary from weak to strong fogs (extinction and absorption coefficients from $7.8 \times 10^{-6} \mathrm{~m}^{-1}$ to $1.36 \times 10^{-2} \mathrm{~m}^{-1}$ and $7.40 \times 10^{-6} \mathrm{~m}^{-1}$ to $7.65 \times 10^{-3} \mathrm{~m}^{-1}$ at $11 \mu \mathrm{m}$, and $W$ from $6.89 \times 10^{-5} \mathrm{~g} \mathrm{~m}^{-3}$ to $1.29 \times 10^{-1} \mathrm{~g} \mathrm{~m}^{-3}$, see Table 1). They encompass the values considered by Pinnick et al. (1979).

The extinction coefficients and liquid water contents of the 20 fog cases are shown with diamonds on Figs. 3 and 4 for the laser wavelengths of $4 \mu \mathrm{m}$ and $11 \mu \mathrm{m}$, respectively. Each diamond has an abscissa given by Eq. (2) and an ordinate by Eq. (3). The solid line is the linear approximation Eq. (5) $\left(c_{\mathrm{e}}(4 \mu \mathrm{m})=0.64 ; c_{\mathrm{e}}(11 \mu \mathrm{m})=0.31\right)$. The results are similar to those of Pinnick et al. (1979). At $\lambda=4 \mu \mathrm{m}$, the dots are off the black line and dispersed. There seems to be no particular relationship between both parameters independent of the size distribution. At $\lambda=11 \mu \mathrm{m}$ however, the diamonds and the line suggest that the linear approximation holds. As several size distributions include a significant fraction of large droplets, Pinnick's linear approximation Eq. (5) appears to be still applicable in practice.

In Figs. 5 and 6 are drawn the two functions

$F(r)=\frac{4 \pi}{3} \rho_{\mathrm{H}_{2} \mathrm{O}} r^{3}$ 


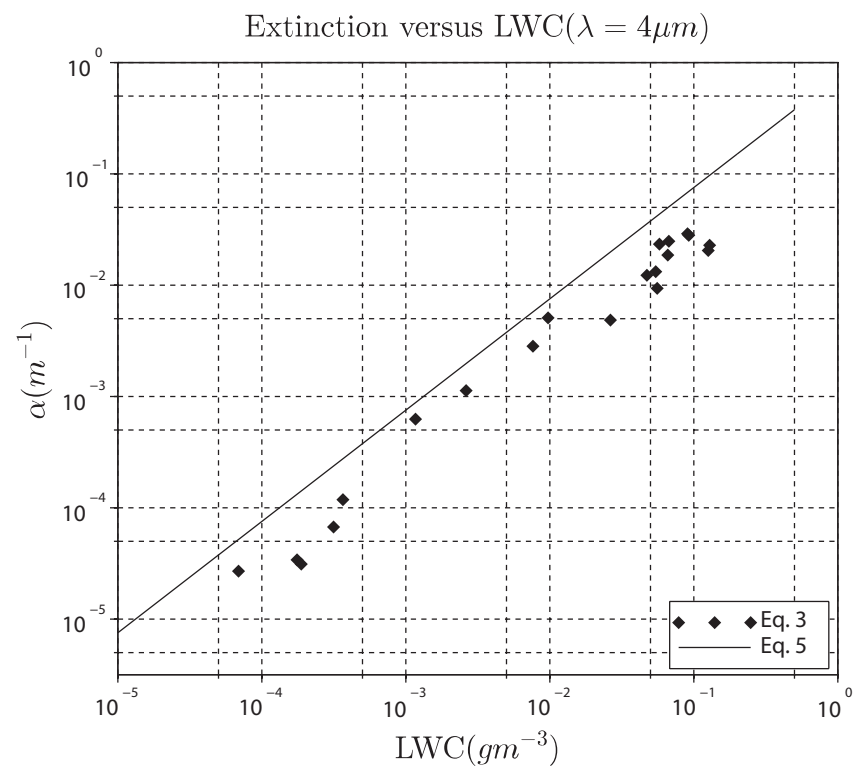

Fig. 3. Extinction coefficients versus LWC at $\lambda=4 \mu \mathrm{m}$ for the 20 size distributions considered in the paper. Each diamond has an abscissa equal to the LWC computed with Eq. (2) and an ordinate equal to the extinction coefficient computed with Eq. (3.) The solid line is the linear approximation proposed by Pinnick et al. (1979) (Eq. 5).

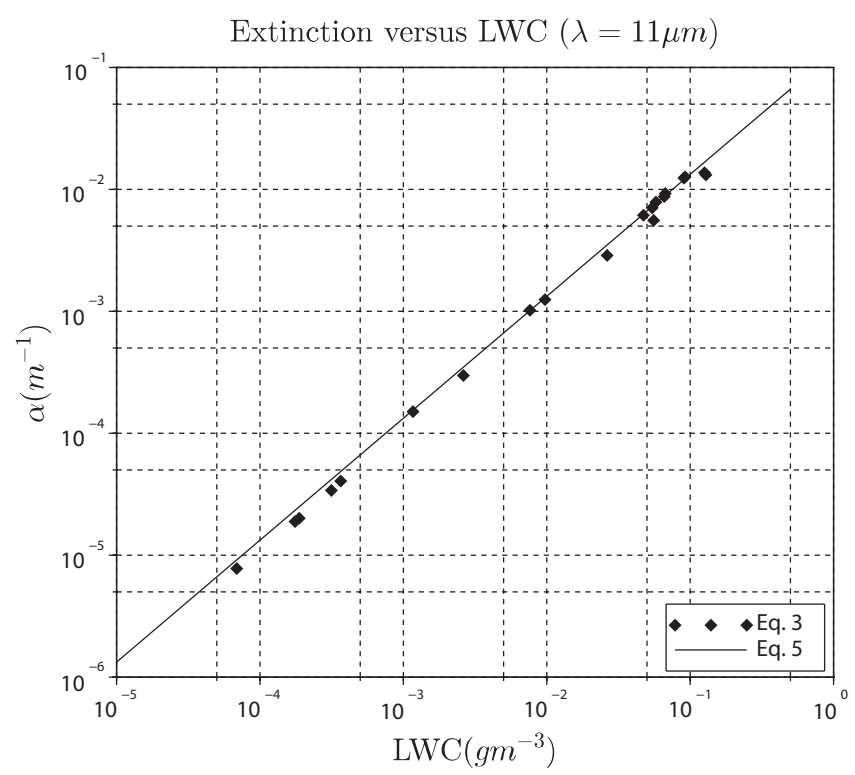

Fig. 4. As Fig. 3, for $\lambda=11 \mu \mathrm{m}$.

and

$\hat{F}(r)=\frac{210^{12} \lambda \rho_{\mathrm{H}_{2} \mathrm{O}}}{3 \pi c_{\mathrm{e}}(\lambda)} r^{2} Q_{\mathrm{ext}}(r, \lambda, m)$.

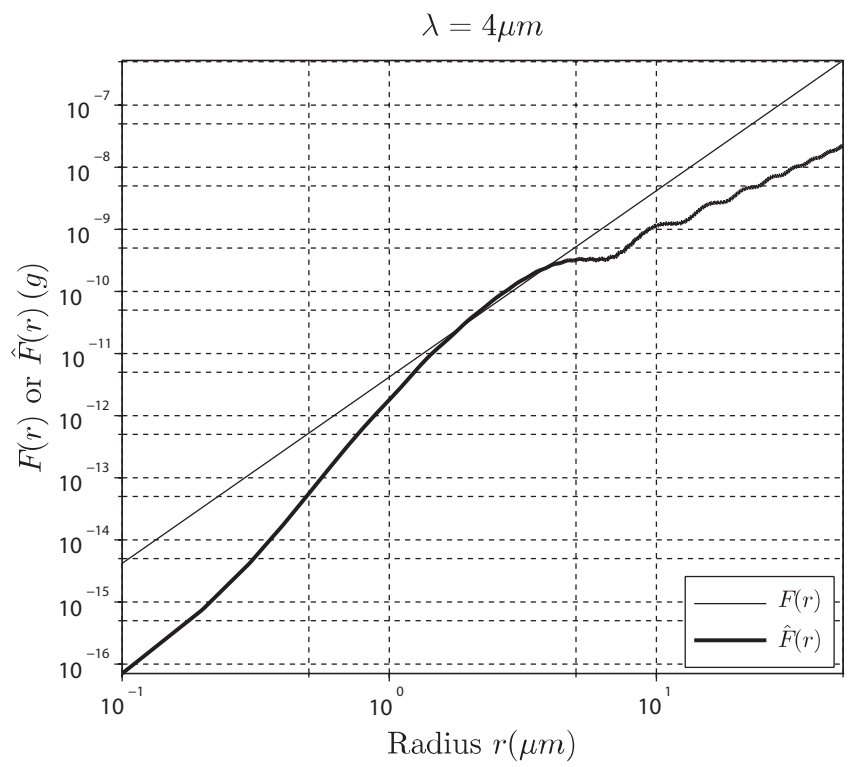

Fig. 5. Functions $F(r)$ and $\hat{F}(r)$ defined in Eqs. (6) and (7) as a function of the droplet radius $r$ for $\lambda=4 \mu \mathrm{m}$.

These functions are the contributions to $W$ and $\hat{W}$ of a single particle of radius $r$ since

$W=\int_{0}^{+\infty} F(r) n(r) \mathrm{d} r$

and

$\hat{W}=\int_{0}^{+\infty} \hat{F}(r) n(r) \mathrm{d} r$.

They are drawn for $\lambda=4 \mu \mathrm{m}$ (Fig. 5) and $\lambda=11 \mu \mathrm{m}$ (Fig. 6), and the relative difference $|1-\hat{F} / F|$ is displayed for both wavelengths in Figs. 7 and 8 . At $4 \mu \mathrm{m}, \hat{W}$ is a poor approximation to $W$ except for particles in the range $[2 \mu \mathrm{m}, 4 \mu \mathrm{m}]$. Outside this interval, the contribution of the particles to the LWC is grossly underestimated. At $11 \mu \mathrm{m}$, the approximation is much better and holds for particles in a much wider range. The relative error is less than $10 \%$ for radii between $1.7 \mu \mathrm{m}$ and $13.2 \mu \mathrm{m}$. This result is noticeable as observations suggest a vast majority of fogs contain particles within this range. Larger particles may be found, but are in very small numbers and therefore shall not contribute much to the total LWC. Fog extinction coefficients thus seem to be an accurate proxy for their liquid water content.

\section{Impact of the refractive index}

As already mentioned, the results above are all based on extinction efficiencies calculated with the refractive index of 


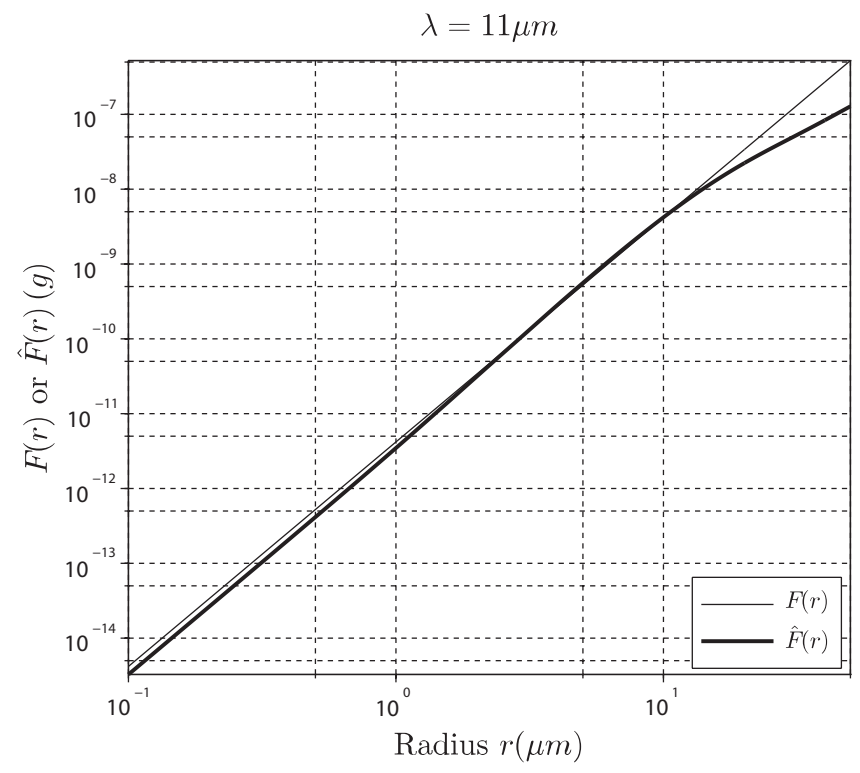

Fig. 6. As Fig. 5 , for $\lambda=11 \mu \mathrm{m}$.

water, that is, assuming fog particles mainly consist of water. This assumption is common in fog models or fog studies (Dumont, 2000; Elias et al., 2009; Rangognio et al., 2009; Khain et al., 2004; Laven, 2011; Boers et al., 2013). However, fog particles are formed from condensation nuclei (Pruppacher and Klett, 2010), that is, aerosol, which refractive index depends on its chemical composition and can vary a lot. In large fog particles, the amount of water is large and the use of the refractive index of water is probably justified. But fogs contain small particles in large numbers, and the relative contribution of the nucleus in the overall matter of the particle may not be negligible. This is why we have studied the impact of the value of the refractive index on the $W$ versus extinction relationship. To our knowledge, there are no measurements of the refractive index of fog particles in the literature, so the interval of variation of the index, if any, is not known. Consequently, we did not try to see if real fluctuations of the refractive index of fog particles may or may not have an impact of how $W$ relates to the extinction, but rather tried to determine the interval of variations the refractive index may have before it has a significant impact. We leave it to future studies to determine whether real refractive indices are within this interval or exceed it.

We proceeded in three steps. First, keeping the real value of the refractive index, we modified the imaginary part by default or excess until we found a significant impact on the extinction coefficients of the 20 PARISFOG size distributions. Second, we did the same keeping this time the imaginary part constant and tuning the real part. Finally, we made the assumption that particles with a diameter larger than $1 \mu \mathrm{m}$ are mainly made of water (the extinction coefficient for these particles is computed with the refractive index of water), and smaller particles of another matter. We considered several

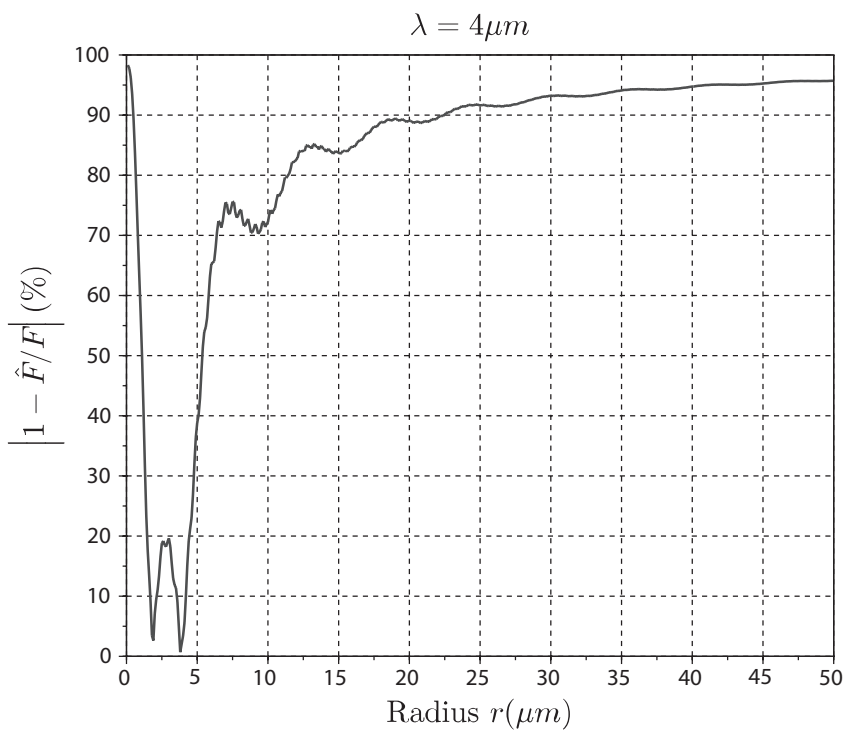

Fig. 7. Relative difference $|1-\hat{F} / F|$ between $F(r)$ and $\hat{F}(r)$ (in $\%$ ) for $\lambda=4 \mu \mathrm{m}$.

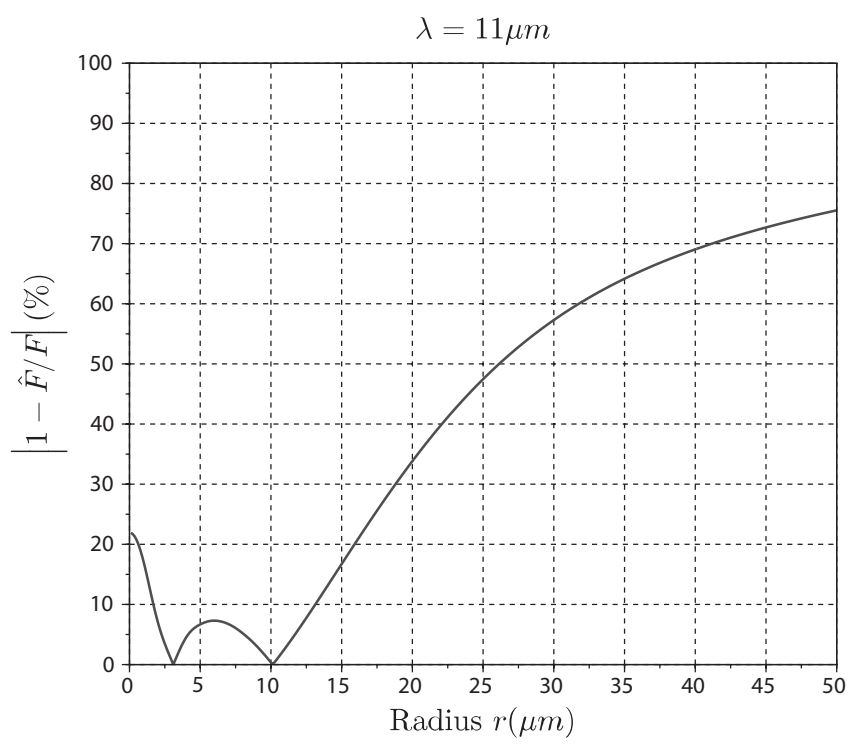

Fig. 8. As Fig. 7, for $\lambda=11 \mu \mathrm{m}$.

possible matters commonly found in aerosols and their corresponding refractive indices (see Table 2 from Fenn et al., 1985).

Figure 9 shows how the relationship between extinction and LWC varies as a function of the imaginary part of the refractive index. The extinction computed with the index of water (cross) is the reference. Two indices have larger imaginary parts (filled circle and filled square), and two are smaller (open circle and square). The way that these values were obtained is explained in Fig. 10. In the top panel are drawn the extinction efficiencies for $m_{\mathrm{w}}=1.153+i 0.0968$ (water - the reference), $m=1.153+i 0.129$ (filled square in Fig. 9) 


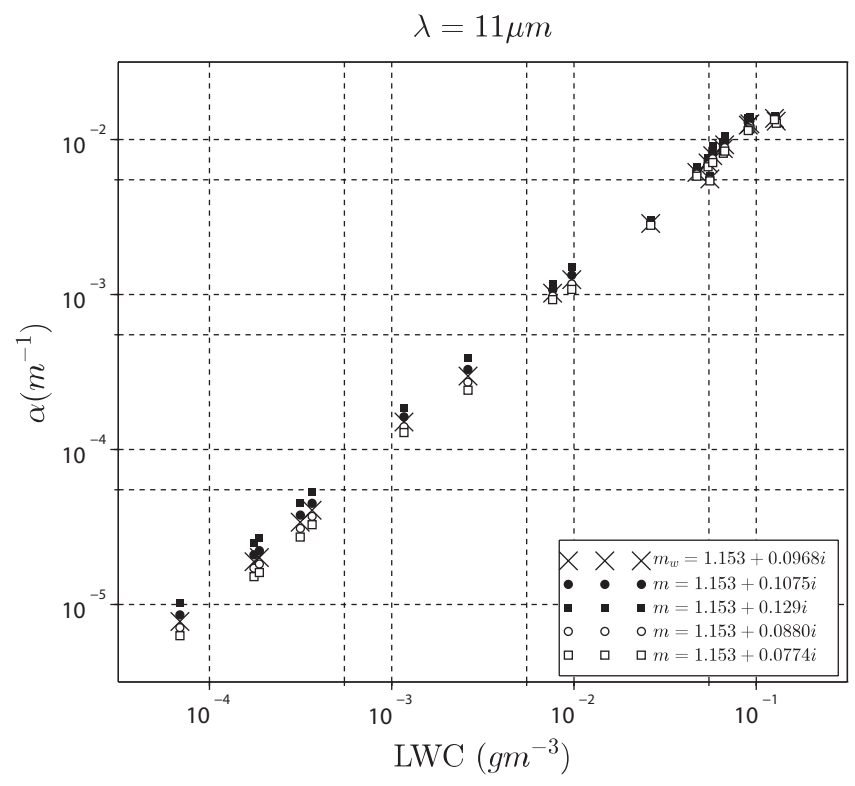

Fig. 9. Extinction coefficients (as a function of the liquid water content) for the 20 size distributions of PARISFOG for a refractive index with a variable imaginary part. The reference is the refractive index of water $m_{\mathrm{w}}=1.153+0.0968 i(x)$. The circles and squares are for the refractive indices that produce maximum extinction efficiency relative errors of $10 \%$ and $25 \%$ respectively, in excess (filled) or default (open).

and $m=1.153+i 0.077$ (open square in Fig. 9). The latter is below the water index, the former is above, but we see in the bottom panel that both produce a maximal relative difference $100 \%\left(Q_{\text {ext }}(r, \lambda, m) / Q_{\text {ext }}\left(r, \lambda, m_{\mathrm{w}}\right)-1\right)$ of $\pm 25 \%$ with respect to water. The other indices in Fig. 9 (filled and open circles) were selected because they produce absolute relative errors of $10 \%$. In Fig. 9, we can see that the extinction coefficients grow when the imaginary part of the index is above water and diminish when it is below. The reason is simple: the absorption grows with the imaginary part of the index. The impact of the value of the imaginary part of the index is more pronounced when the LWC is small. The explanation for this is given in Fig. 10. There we can see that the relative difference of $Q_{\text {ext }}$ to pure water is larger for radii less than $10 \mu \mathrm{m}$ than above. Fogs with small LWC are mainly formed by small particles.

The impact of the real part of the refractive index is studied in Figs. 11 and 12. The refractive indices considered for the curves in Fig. 10 were chosen so as to produce a maximum relative difference with pure water of $10 \%$ (circles) and $25 \%$ (squares). The impact on the extinction coefficients are of the same order as in Fig. 9, but this time the relative variation in the index is about five times smaller. It thus appears here that extinction coefficients are more sensitive to the real part of the refractive index than the imaginary part. The most striking feature is that the sensitivity to the real part of the index is growing with the LWC. The reason is explained in
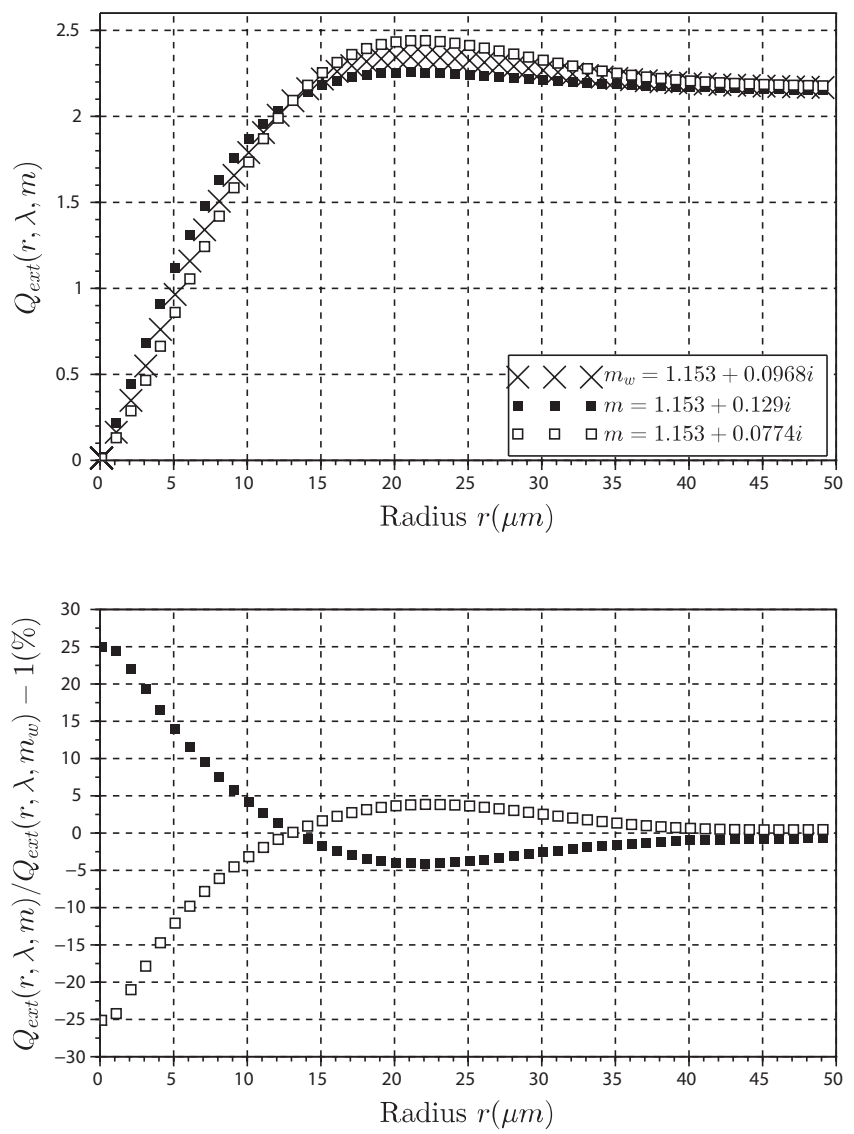

Fig. 10. Extinction efficiencies (top) for the refractive indices $m_{\mathrm{W}}=1.153+i 0.0968$ (water), $m=1.153+i 0.129$ and $m=1.153+i 0.0774$, and relative difference (in \%) to pure water (bottom). The relative difference is equal to $100 \%$ $\left(Q_{\text {ext }}(r, \lambda, m) / Q_{\text {ext }}\left(r, \lambda, m_{\mathrm{W}}\right)-1\right)$. The laser wavelength is $11 \mu \mathrm{m}$.

Table 2. Refraction index of different aerosol types. From Fenn et al. (1985).

\begin{tabular}{ll}
\hline Sea salt & $1.48+1.4 \times 10^{-2} i$ \\
Oceanic & $1.246+7.31 \times 10^{-2} i$ \\
Ice & $1.093+0.239 i$ \\
Meteoric & $1.509+0.691 i$ \\
Water Soluble & $1.72+5.0 \times 10^{-2} i$ \\
Dust & $1.62+0.105 i$ \\
Soot & $2.23+0.73 i$ \\
$75 \% \mathrm{H}_{2} \mathrm{SO}_{4}$ & $1.670+0.485 i$ \\
Volcanic & $2.15+0.270 i$ \\
\hline
\end{tabular}

Fig. 12. There we can see that the relative difference of $Q_{\text {ext }}$ is maximum for radii of the order of $10 \mu \mathrm{m}$ and remains large for radii up to $20 \mu \mathrm{m}$. For small radii, the relative difference grows steadily with the radius, but it is less than $5 \%$ up to a radius of $\sim 2 \mu \mathrm{m}$. Light fogs with small particles are thus less affected. 


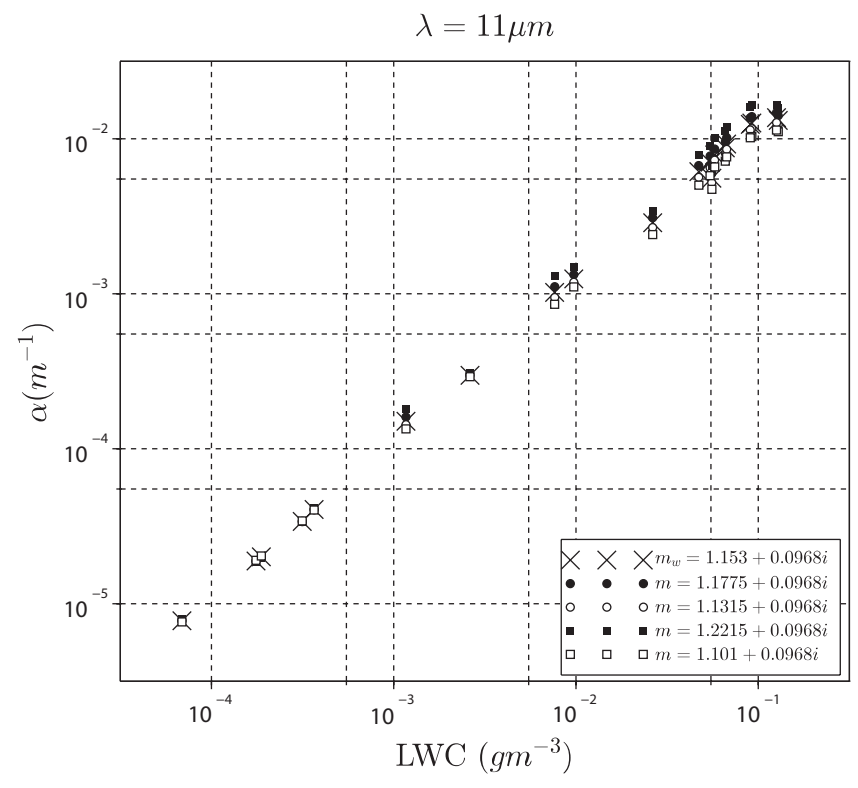

Fig. 11. As Fig. 9, for refractive indices with a variable real part.
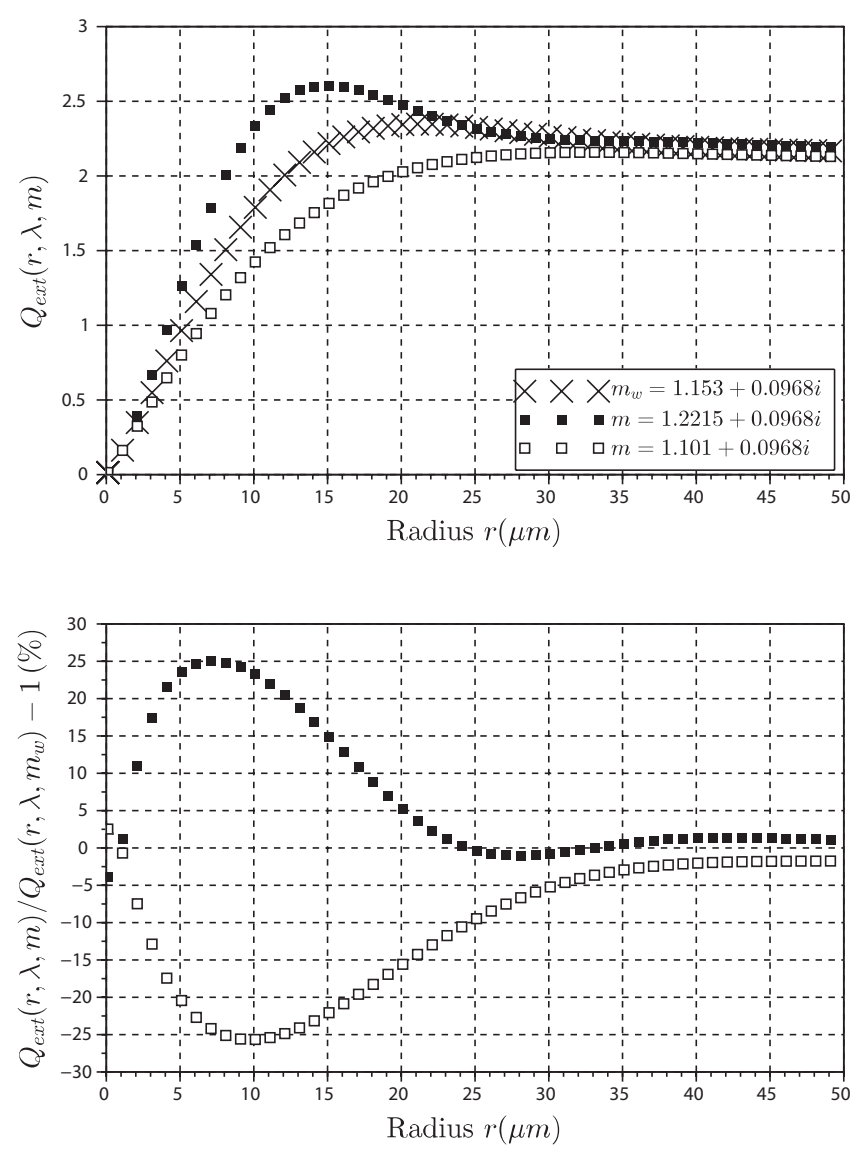

Fig. 12. As Fig. 10, for varying real parts of the fog droplet refractive index.

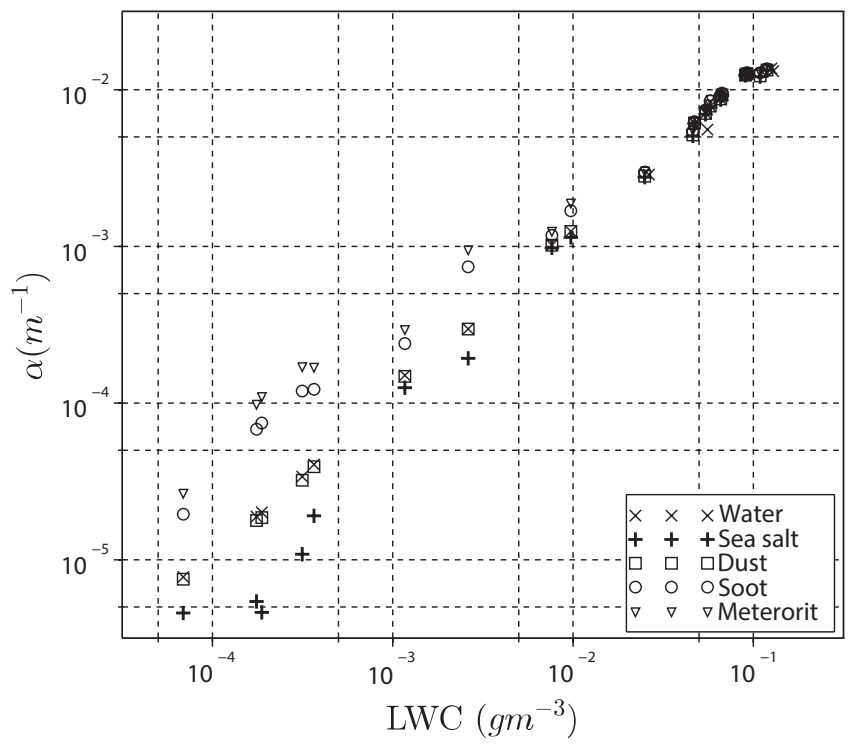

Fig. 13. Extinction coefficient versus liquid water content for the 20 fog cases studied and a refractive index of one particular aerosol type for particles with radii $<1 \mu \mathrm{m}$ and pure water above (see Eq. (10)). Four different aerosol types are considered: sea salt $(+)$, dust (square), soot (circles) and meteoric particles (triangles). For each type, the refractive index is taken from Fenn et al., 1985 (see Table 2). The extinction coefficients for a refractive index of pure water for all particle radii are given for comparison with $\times$ symbols.

In Fig. 13, the extinction coefficients (open diamonds) are computed in the following way:

$$
\begin{aligned}
\alpha(\lambda) & =10^{-6} \pi\left[\int_{0}^{1 \mu \mathrm{m}} r^{2} Q_{\text {ext }}(r, \lambda, m) n(r) \mathrm{d} r\right. \\
& \left.+\int_{1 \mu \mathrm{m}}^{+\infty} r^{2} Q_{\text {ext }}\left(r, \lambda, m_{\mathrm{w}}\right) n(r) \mathrm{d} r\right]
\end{aligned}
$$

with $m$ the refractive index of several types of aerosols (taken from Fenn et al., 1985; see Table 2). This means that small particles with radii less than $1 \mu \mathrm{m}$ are considered pure aerosols and pure water drops above. They are compared to reference extinction coefficients computed with the refractive index of pure water for all radii $(x)$. The wavelength is $11 \mu \mathrm{m}$. As can be expected, fogs with heavy LWC are not affected by the value of the refractive index as their liquid water content is dominated by large particles with radii above $1 \mu \mathrm{m}$. The impact of the refractive index is on the contrary visible when the LWC is light. This is because the particle size distribution is then mostly composed of small particles. The extinction coefficient may vary over at least one decade depending on which type of aerosol is chosen. The curves show that the impact of the aerosol type can still be visible with LWCs up to $\sim 0.01 \mathrm{~g} \mathrm{~m}^{-3}$. According to the statistics published by Burnet et al. (2012), less than $10 \%$ of LWC 
measurements performed at SIRTA during the winters 2010 2011 and 2011-2012 were below this value. This suggests that a vast majority of LWCs derived from IR optical extinction measurements should not be affected by the precise nature of the condensation nuclei.

\section{Conclusions}

The study reported here shows that Pinnick's results published in the late 1970s are still valid when fog size distributions contain large droplets. At $\lambda=11 \mu \mathrm{m}$ (thermal IR) the proportionality between the extinction coefficient and the LWC seems to be verified, the linear approximation of the extinction efficiency being good for droplet radii as large as $14 \mu \mathrm{m}$. At $4 \mu \mathrm{m}$, there is no clear relationship between the LWC and the extinction coefficient. Scatter plots show that close LWCs can be associated to extinction coefficients with significant differences depending on the actual size distribution so it cannot be used as a proxy for the LWC.

The study is based on a limited number of fog cases, all of them obtained on the same experimental site where fogs are mostly caused by radiative cooling at the surface. On this site, the results suggest that fog droplets with larger radii are scarce and do not contribute significantly to the overall LWC. It remains to be verified that this is still true for other fog types in other places. If that is so, Pinnick's linear approximation of the extinction efficiency opens a real possibility to measure vertical profiles of the LWC in fogs with a rather simple backscatter lidar operating in the thermal infrared. The size and power of such a lidar is not discussed here and is left for a future publication. Preliminary studies on the subject suggest that a maximum range of several hundreds of metres should be possible with commercial $\mathrm{CO}_{2}$ lasers. This range is comparable to the typical vertical extension of fogs (Dabas et al., 2012), so a profiling of the LWC through the entire fog thickness seems to be possible.

The major limitation found in this work is due to a possible uncertainty on the refractive index of particles detected by the lidar. Small particles contain a significant fraction of aerosol matter with a refractive index that may differ significantly from water. Our study suggests that thick fogs with heavy LWC are unlikely to be affected, but thin fogs may be. For these fogs, it seems that LWC measurement is mostly sensitive to the real part of the refractive index.

Acknowledgements. The data used in this paper were measured on the SIRTA site in the frame of the research programme PREVIBOSS. The authors thank the SIRTA team for the provision of data and GAME colleagues Frédéric BURNET and Thierry BOURRIANE who helped select interesting fog cases, processed raw Welas 2000 and FM 100 data into composite size distributions, and answered many questions about size distribution sensors and size distributions in fogs. The works reported was supported by the Délégation Générale pour l'Armement (French armament agency).
Edited by: F. S. Marzano

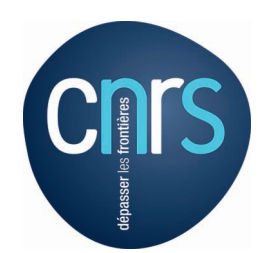

The publication of this article is financed by CNRS-INSU.

\section{References}

Bergot, T: Small-scale structure of radiation fog: a large-eddy simulation study, Q. J. Roy. Meteorol. Soc., 139, 1099-1112, doi:10.1002/qj.2051, 2013.

Bergot, T. and Guédalia, D.: Numerical forecasting of radiation fog, Part I: Numerical model and sensitivity tests, Mon. Weather Rev., 122, 1218-1230, 1994.

Boers, R., Klein Baltink, H., Hemink, H. J., Bosveld, F. C., and Moerman, M.: Ground-Based Observations and Modeling of the Visibility and Radar Reflectivity in a Radiation Fog Layer, J. Atmos. Ocean. Technol., 30, 288-300, doi:10.1175/JTECH-D-12$00081.1,2013$.

Bohren, C. F. and Huffman, D. R.: Absorption and scattering of light by small particles, Wiley Interscience, 1983.

Burnet, F., Gomes, L., Haeffelin, M., Dupont, J.-C., and Elias, T.: Analysis of the microphysical structures of fog during the PARISFOG project, Proceeding of 16th International Conference on Clouds and Precipitation, Leipzig, Germany, July 2012, Am. Meteorol. Soc., 2012.

Chylek, P.: Extinction and Liquid Water Content of Fogs and Clouds, J. Atmos. Sci., 35, 296-300, 1978.

Dabas, A., Remy, S., and Bergot, T.: Use of a sodar to improve the forecast of fogs and low level clouds on airports, Pure Appl. Geophys., 169, 769-781, doi:10.1007/s00024-011-0334-y, 2012.

Dumont, E.: Caractérisation, modélisation et simulation des effets visuels du brouillard pour l'usager de la route, $\mathrm{PhD}$ Thesis, Paris V René Descartes University, 2002.

Elias, T., Haeffelin, M., Drobinksi, P., Gomes, L., Rangognio, J., Bergot, T., Chazette, P., Raut, J.-C., and Colomb, M.: Particulate contribution to extinction of visible radiation: Pollution, haze, and fog, Atmos. Res., 92, 443-454, doi:10.1016/j.atmosres.2009.01.006, 2009.

Elias, T., Jolivet, D., Dupont, J.-C., Haeffelin, M., and Burnet, F.: Preliminary results of the PreViBOSS project: description of the fog life cycle by ground based and satellite observation, SPIE Proceedings, 8534, 853406, doi:10.1117/12.974709, 2012.

Fenn, R. W., Clough, S. A., Gallery, W. O., Goods, R. E., Kneizys, F. X., Mill, J. D., Rothmann, L. S., Shettle, E. P., and Voltz, F. E.: Optical and infrared properties of the atmosphere, in: Handbook of Geophysics and the Space Environment, edited by: Jursa, A. S., Air Force Geophysics Laboratory, 1023 pp., 4th Edn., 1985.

Gerber, H.: Direct measurement of suspended particulate volume concentration and far-infrared extinction coefficient with a laserdiffraction instrument, Appl. Optics, 30, 4824-4831, 1991.

Gultepe, I. (Ed.): Fog and Boundary Layer Clouds: Fog Visibility and Forecasting, Special issue of Pure and Applied Geophysics, 164, 316 pp., 2007. 
Guyon, P., Boucher, O., Graham, B., Beck, J., Mayol-Bracero, O. L., Roberts, G. C., Meanhaut, W., Artaxo, P., and Andreae, M. O.: Refractive index of aerosol particles over the Amazon tropical forest during LBA-EUSTACH 1999, Aerosol Sci., 34, 883-907, doi:10.1016/S0021-8502(03)00052-1, 2003.

Haeffelin, M., Barthès, L., Bock, O., Boitel, C., Bony, S., Bouniol, D., Chepfer, H., Chiriaco, M., Cuesta, J., Delanoë, J., Drobinski, P., Dufresne, J.-L., Flamant, C., Grall, M., Hodzic, A., Hourdin, F., Lapouge, F., Lemaître, Y., Mathieu, A., Morille, Y., Naud, C., Noël, V., O'Hirok, W., Pelon, J., Pietras, C., Protat, A., Romand, B., Scialom, G., and Vautard, R.: SIRTA, a ground-based atmospheric observatory for cloud and aerosol research, Ann. Geophys., 23, 253-275, doi:10.5194/angeo-23-253-2005, 2005.

Haeffelin, M., Bergot, T., Elias, T., Tardif, R., Carrer, D., Chazette, P., Colomb, M., Drobinski, P., Dupont, E., Dupont, J.-C., Gomes, L., Musson-Genon, L., Pietras, C., Plana-Fattori, A., Protat, A., Rangognio, J., Raut, J.-C., Rémy, S., Richard, D., Sciare, J., and Zhang, X.: PARISFOG Shedding new light on fog physical processes, Bull. Am. Meteor. Soc., 91, 767-783, doi:10.1175/2009BAMS2671.1, 2010.

Hale, G. M. and Querry, M. R.: Optical constants of water in the 200-nm to 200- $\mu \mathrm{m}$ wavelength region, Appl. Optics, 12, 555$563,1973$.

ICAO Circular 135/AN156: Final report and comments from the Netherlands aviation safety board of the investigation into the accident with the collision of KLM flight 4805, Boing 747-206B, PH-BUF and Pan American flight 1736, Boing 747-12; N736PA at Tenerife airport, Spain, on 27 March 1977.

Khain, A., Arkhipov, V., Pinsky, M., Feldman, Y., and Ryabov, Y. A.: Rain enhancement and fog ilimination by seeding with charged droplets: Part I: Theory and numerical simulations, J. Appl. Meteorol., 43, 1513-1529, 2004.
Laven, P.: Time domain analysis of scattering by a water droplet, Appl. Optics, 50, F29-F38, 2011.

Mätzler, C.: MATLAB functions for Mie scattering and absorption version 2. Research Report No. 2002-11, Institute of Applied Physics, University of Bern, 2002.

Mie, G.: Beiträge zur Optik trüber Medien speziell kolloidaler Metallösungen. Ann. Phys, 25, 377-445, 1983.

Pinnick, R. G., Hoihjelle, D. L., Fernandez, G., Stenmark, E. B., Lindberg, J. D., Hoidale, G. B., and Jennings, S. G.: Vertical structure in atmospheric fog and haze and its effects on visible and infrared extinction, J. Atmos. Sci., 35, 2020-2032, 1978.

Pinnick, R. G., Jennings, S. G., Chylek, P., and Auvermann, H. J.: Verification of a linear relation between IR extinction, absorption and liquid water content of fog, J. Atmos. Sci., 36, 1577-1586, 1979.

Pruppacher, H. R. and Klett, J. D.: Microphysics of Clouds and Precipitation, Springer Netherlands, doi:10.1007/978-0-306-481000_8, 2010.

Rangognio, J.: Impact des aérosols sur le cycle de vie du brouillard, PhD Thesis, Toulouse III Paul Sabatier University, 2009.

Rémy, S. and Bergot, T.: Assessing the impact of observations on a local numerical fog prediction system, Q. J. Roy. Meteorol. Soc., 135, 1248-1265, doi:10.1002/qj.448, 2009.

Spiegel, J. K., Zieger, P., Bukowiecki, N., Hammer, E., Weingartner, E., and Eugster, W.: Evaluating the capabilities and uncertainties of droplet measurements for the fog droplet spectrometer (FM-100), Atmos. Meas. Tech., 5, 2237-2260, doi:10.5194/amt5-2237-2012, 2012.

Sullivan, K. and Jordan, M.: Travelers slowed, stranded as dense fog cloaks London, The Washington Post, Friday, December 22, available at: http://www.washingtonpost.com/wp-dyn/ content/article/2006/12/21/AR2006122101535.html, 2006. 